\title{
An Overview of Frequency Control as a Criterion of Power System Reliability and International Survey of Determining Operating Reserve
}

\author{
Md Saleh Ebn Sharif ${ }^{1, ~ *, ~ M a h m u d-U l-T a r i k ~ C h o w d h u r y ², ~ M d ~ J a n a t u l ~ F e r d o u s ~}{ }^{3}$, \\ Md Moniruzzaman ${ }^{1}$, Md Monower Zahid Khan ${ }^{4}$ \\ ${ }^{1}$ Department of Electrical and Electronic Engineering, Bangladesh University of Engineering and Technology, Dhaka, Bangladesh \\ ${ }^{2}$ Department of Electrical and Computer Engineering, Northeastern University, Boston, MA, USA \\ ${ }^{3}$ Department of Electrical, Electronic and Communication Engineering, Military Institute of Science and Technology, Dhaka, Bangladesh \\ ${ }^{4}$ School of Electrical and Electronic Engineering, University of Manchester, Manchester, UK
}

\section{Email address:}

Saleh.electrical07@gmail.com (Md S. E. Sharif)

${ }^{*}$ Corresponding author

\section{To cite this article:}

Md Saleh Ebn Sharif, Mahmud-Ul-Tarik Chowdhury, Md Janatul Ferdous, Md Moniruzzaman, Md Monower Zahid Khan. An Overview of Frequency Control as a Criterion of Power System Reliability and International Survey of Determining Operating Reserve. International American Journal of Modern Energy. Vol. 3, No. 5, 2017, pp. 101-114. doi: 10.11648/j.ajme.20170305.14

Received: October 6, 2017; Accepted: October 23, 2017; Published: October 28, 2017

\begin{abstract}
In this paper an extensive literature review of power system frequency control regulation and in relation to this, operating reserve determination policy have been highlighted. In terms of power system reliability and stability aspect, frequency control mechanism is the most important factor; hence there is a need for sufficient capacity reserve in case of contingency. An investigation of operating reserve policy in different regions, e.g., US, Canada, Europe and Asia have been conducted to clearer understand of reserve policy. It has been identified that, probabilistic approach is the best suited for determining generation adequacy in terms of economic and reliability point of view. Different type of reserve is allocated at different level of frequency control level. So, technical specification and timing for frequency control level of different system operator have been discussed widely. A comparison of frequency control framework between European and US is also presented. To ensure reliability and stability, it is recommended to adopt special protection scheme alongside new technologies - WAMS, SmartGrid.
\end{abstract}

Keywords: Frequency Control, Operating Reserve, Reliability, Ancillary Services, Probabilistic Approach, Power System Operation, Energy Efficiency, Renewable Integration

\section{Introduction}

From an operational point of view, power systems are affected by factors that change each second, minute, hour, day, season, and year. In each time frame of operation, it is necessary that balance be kept between the load on the system and the available supply in order for system frequency to remain in an acceptable range. In the very short time frames (seconds-to-minutes), bulk power system reliability is almost entirely maintained by natural inertia and automatic equipment and control systems, such as generators governor system and the power system's automatic generation control (AGC) [1]. In the intermediate to longer time frames, economic dispatch mechanisms, system operator's actions and operational planner's edicts become the primary factors to maintaining system reliability. Generally, frequency regulation is one of the most significant challenges for system operators. The system frequency deviations must be maintained within a narrow range for three basic reasons:

a). Customers, particularly those managing industrial processes, are highly sensitive to frequency deviations from the nominal level;

b). Generating units are designed to operate most efficiently at their nominal speed and subject to damage if operated beyond certain frequency bounds;

c). Automatic protection systems will disconnect load and 
generation if the system frequency drops below a certain value.

Therefore, in order to keep a balance between generation and consumption at all times, the load is forecasted and sufficient generation is committed and dispatched to maintain supply/demand balance [4]. However, since the demand forecast is never $100 \%$ accurate and since unpredictable contingencies (forced outages) like generator and network trips may occur in power systems, the generation and consumption will experience mismatch on regular basis. This unbalance can cause reduction or increase of system frequency. As a result, the system frequency frequently deviates from its nominal value jeopardizing the stability and hence reliability of power system [5]. Consequently, the system operator needs suitable resources to maintain system frequency and guarantee security and stability (reliability) of power system operation. These resources, commonly referred to as reserves should be available at the right time in order to keep power system frequency in an acceptable range [2, 3]. In other words, frequency control requires that a certain amount of active power to be kept in reserve to be able to regain the balance between demand and generation at all times. Generally, reserve consists of upward and downward reserves that both of them are required for maintenance of stability and frequency [6]. When the amount of generation is more than demand, the downward reserve is utilized to retain frequency by automatically reducing generation. Upward reserve refers to available generation capacity (or voluntary and controlled load reduction) that is added to the power system in order to maintain the frequency when system suffers from frequency drop (load exceeds generation for any reason).

So from above discussion, it is clear that to make power system more reliable in case of contingency and sudden change of load, system requires generation adequacy, in other words, sufficient operating reserve. In this paper, we have discussed the world wide practice of adopted technique to determine the operating reserve and its methodologies. Then we discussed the frequency control mechanism to withstand the changes in system. As different level of reserve is discussed, we try to correlate the level of reserves are assigned at different level of frequency control mechanisms. After rigorous study of worldwide practice we set a guideline can be adopted in assigning operating reserve at different level of frequency. The remainder of this paper is organized as follows. Second section presents the worldwide practice of operating reserve policy. The third section describes the frequency control mechanism at different level. The fourth section represents the review of modern techniques that have been taken as consideration to make power system 'self healing system'.

\section{International Practice of Operating Reserve}

The function of an electric power system is to provide electricity to its customers efficiently with a reasonable assurance of continuity and quality. The quality of the service is evaluated by the extent to which the supply of electricity is available to customers at a usable voltage and frequency. The reliability of power supply is therefore, related to the probability of providing customers with continuous service at an acceptable voltage and frequency. The indices used to measure generation reliability are probabilistic estimates of the ability of a particular power system configuration, mainly in the form of available generation, to supply the demand. The indices are sensitive to basic factors like generating unit size and availability $[7,8]$. The basic elements used to evaluate generation adequacy are shown in Figure 1. The system is deemed to operate successfully as long as there is sufficient generation to supply the load. Based on this figure, mathematical representations of generation and load are firstly combined to model the risk of supply shortages in the system. Secondly, probabilistic estimates of shortage risk are used as indices of bulk power reliability for the considered configuration [7].

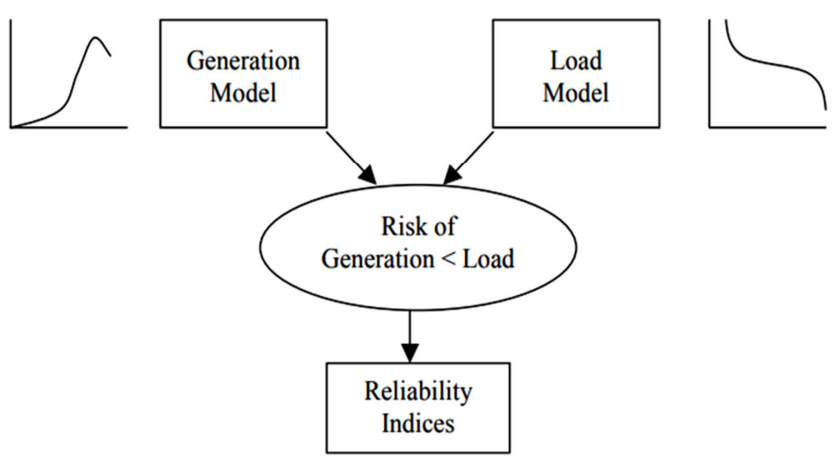

Figure 1. Elements of generation reliability evaluation.

In many power systems, the average duration of interruptions experienced by a customer is just a few hours per year, which translates into high availability of power supply. For decades, satisfactory levels of reliability were achieved through empirical methods and policies. However, as systems grew larger and more complex, formal, more rigorous analytical techniques have been developed and applied.

\subsection{Deterministic Approach for Operating Reserve}

The first techniques, which were used in order to satisfy reliability level, were all deterministic. The deterministic approach is a simple method widely used in the past by the electric utilities to support their planning and operational decisions [9]. In a few words, this approach quantifies the electrical power system reliability using a pre-specified rule based on the experience of the utilities. Therefore, each utility adopted different criteria according to its internal organization and the electrical power system in question. Some of deterministic criteria adopted by different system operators can be found in Table 1. However, these deterministic criteria are not suitable for the reliability assessment of today's electrical power systems. From an economic point of view, this type of deterministic approach leads in most cases to solutions that are wasteful of financial resources without even aiming for a certain 
level of system reliability. The deterministic approach does not directly account for the stochastic behavior of the electrical power systems by its disregard for the way that its components fail and the randomness of the system load. The main advantages of the deterministic approach are the straight forwardness of their results particularly since the criteria used by the utilities were conservatively developed in favor of large supply margins. From the table it's clear that Australian, Canadian, PJM and New Zealand and TSO use deterministic approach of linear programming which assumes the cascading outage and reserves unnecessary resources. In European region, Belgium, France and Netherlands used fixed resources for reserve which does not consider the stochastic nature of load forecast and outage of generating units. For these reasons, the deterministic approach is being gradually replaced by probabilistic methods, although several utilities still use the deterministic approach for determining operating reserve for a power system.

Table 1. Deterministic criteria for reserve requirements of various countries.

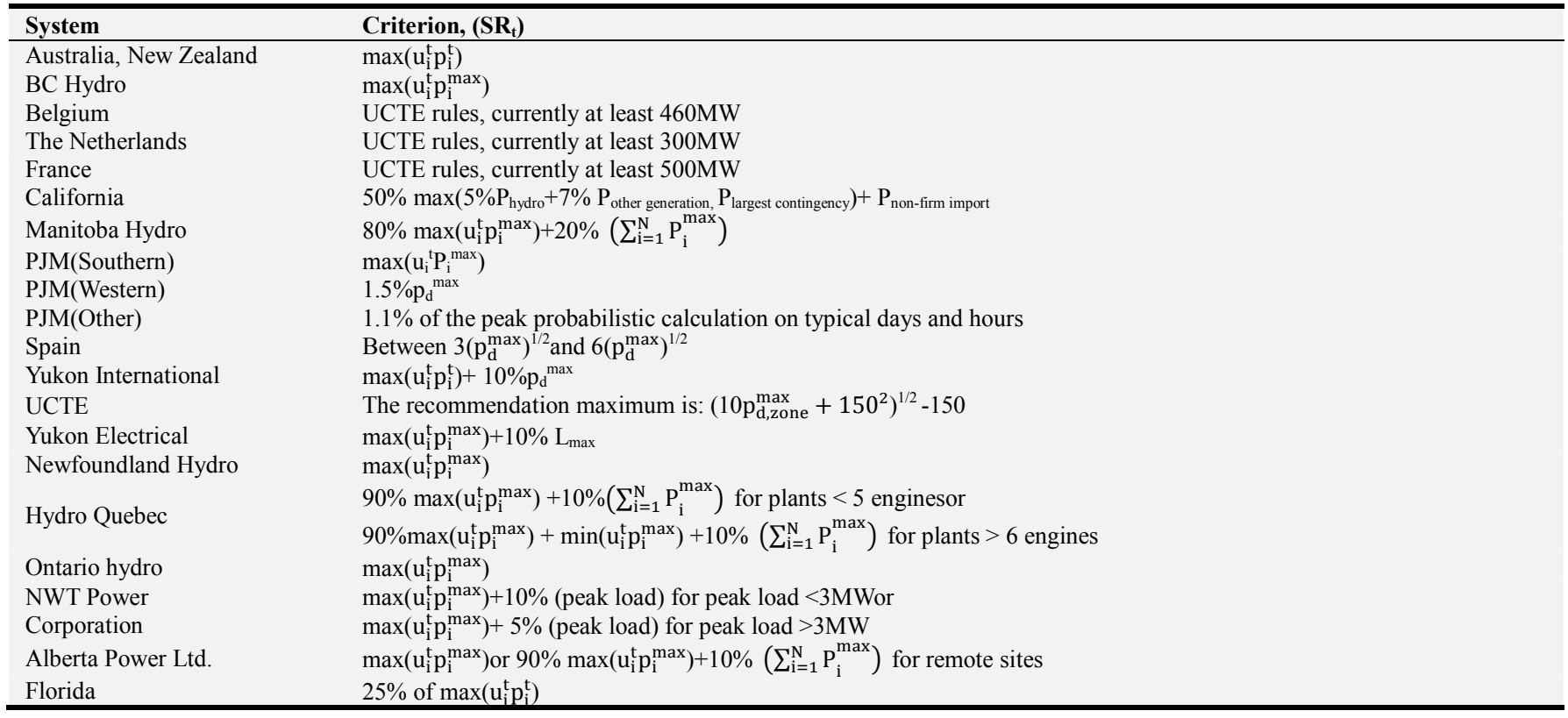

Where:

$L_{\text {max }}$ : the maximum load of the system during a given period

$L_{\text {max } z o n}$ : the maximum load during a given period

$P_{\text {hydro }}$ : scheduled generation from hydroelectric resources

$P_{\text {other generation }}$ : scheduled generation from resources other than hydroelectric

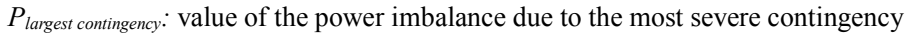

$P_{\text {non-firm import: }}$ total of all the interruptible imports

\subsection{Probabilistic Approach for Operating Reserve}

Probabilistic methods for the determination of operating reserve levels can provide more meaningful information to be used in planning and allocation of system resources. There are two main approaches for probabilistic evaluation of power systems reliability: analytical methods and Monte Carlo simulation $[7,10]$. Analytical techniques represent the system by mathematical models and use direct analytical solutions to evaluate priori reliability indices from the model. Monte Carlo simulation methods estimate reliability indices by simulating the actual random behavior of the system. There are two major types of Monte Carlo simulation methods: the non-chronological type and chronological type. In the non-chronological type, the samples are obtained by producing "snapshots" of the system state, without regard to temporal dependence between samples. Alternatively, in the chronological type, a virtual clock is set in motion and, with the flow of time; sequences of events are randomly generated [11].

Nowadays, there are a number of basic indices which evaluate generation system reliability. These indices include: Loss of Load Probability (LOLP), Loss of Load Expectation (LOLE), Loss of Energy Probability (LOEP), Loss of Energy Expectation (LOEE), Expected Energy Not Served (EENS), Loss of Load Frequency (LOLF) and Loss of Load Duration (LOLD). Currently the most commonly used index is the LOLE [12]. LOLE is the expected number of days or hours in a specified period in which the load exceeds the available generating capacity. A LOLE based method to determine operating reserve has been discussed on our previous work [13]. Generally in probabilistic method, an adequate but varying reserve is determined from period to period to maintain a uniform level of reliability [14]. Then it is required to determine economical but technically suited unit commitment / dispatch, hence there is requirement of appropriate optimization method for least cost operation. So, Large-scale mixed integer programming algorithm, Dynamic programming, Stochastic Optimization (optimal decisions under uncertainty) etc algorithms are used to determine optimal reserve based on reliability risk index [15]. 
Table 2. Least Cost Optimization.

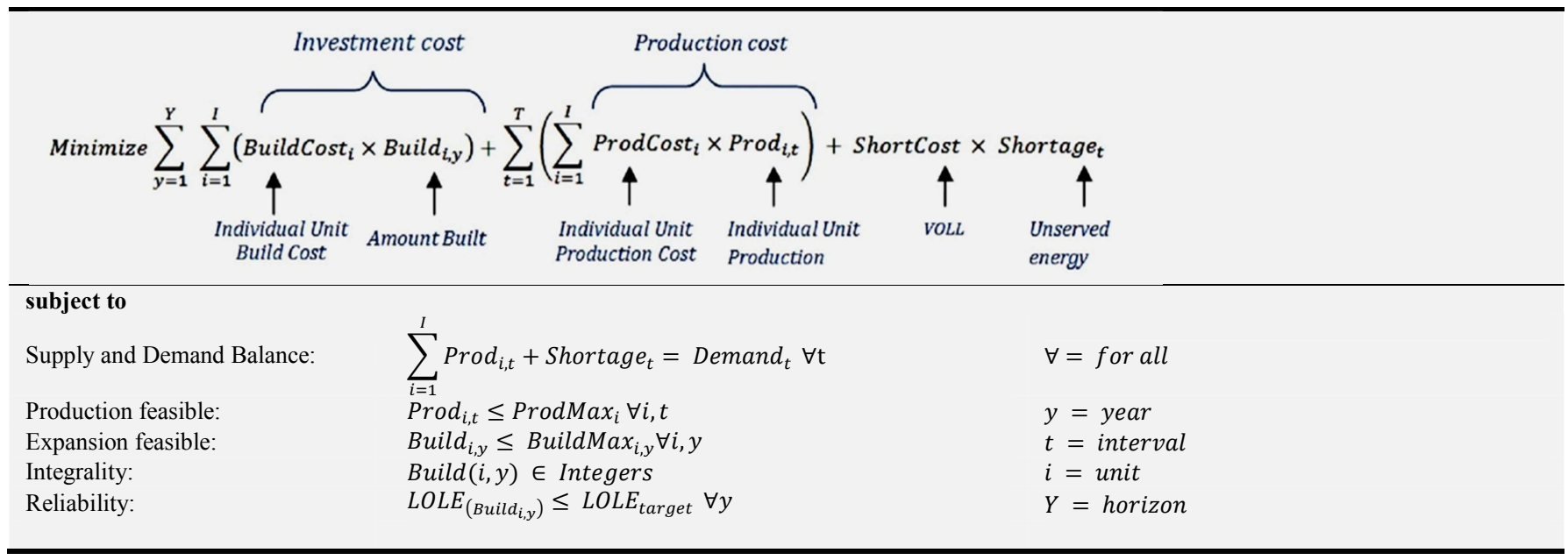

This simplified illustration in table 2 shows a sample of essential elements of the mixed integer programming formulation. Build decisions cover generation, generation cooling types, water use costs, transmission, gas pipeline, coal transport, water pipe, as does supply and demand balance and shortage terms. The entire problem is solved simultaneously, yielding a true co-optimized solution.

So, it is understood that reliability risk index based optimal reserve determination is two staged algorithm. At first, based on risk index amount of capacity reserve is calculated and then optimization for unit commitment. An efficient approach for spinning reserve allocation is described in [16], which proposes to minimize spinning reverse cost (SRC) and unit commitment risk (UCR) [16, 17].

$$
\min T C i=R C(U C R i)+S R C i
$$

A lower UCR indicates a reduction in the cost for loss of load while increasing the cost for reliability. There is always a tradeoff between reliability and cost. So, it is necessary to determine reserve in an efficient way.

\section{Frequency Control as a Criterion of Reliability}

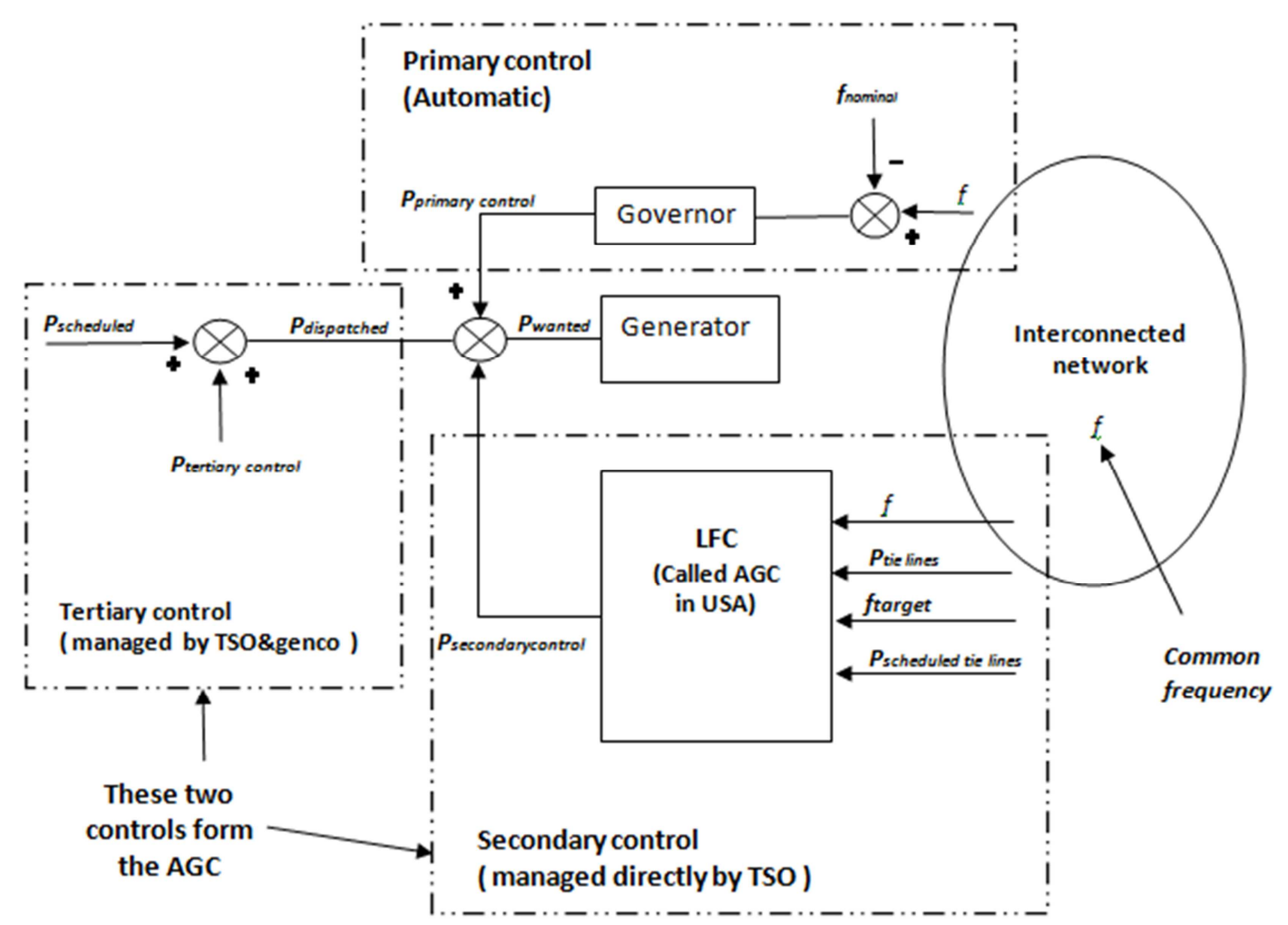

Figure 2. Structure of frequency control within ENTSO. 
NERC defines reliability as the degree to which the performance of electrical system could results in power being delivered to consumers within accepted standards and desired amounts. NERC's definition of reliability encompasses two concepts: adequacy and security [20]. Adequacy is the ability of a power system to supply consumers' electric power and energy requirements at all times. Security is defined as the ability of a power system to withstand sudden disturbances [20, 21]. In a simple manner,generation adequacy refers to the sufficient generation as well as transmission resources are available to meet up the forcasted demand plus reserves for contingencies [58]. Security implies that the power system will remain intact even after outages or equipment failures. Reliability requirements are met by providing ancillary services. As mentioned before, frequency control is known as one of the significant responsibilities for system operators. Frequency control operation is done by various control levels in different times in order to stand against frequency noncompliance in power system. The scheme shown in Figure.2 illustrates the framework that is typically utilized for frequency control in power system. As presented in this figure, frequency control usually involves three levels of controls called Primary, Secondary and Tertiary by ENTSO terminology $[18,19]$.

\subsection{Primary Frequency Control}

Primary frequency control is a mechanism built into synchronous and other type of generators to manage frequency change immediately after such change occurs. As part of primary frequency control, reserve power is managed locally and automatically to arrest frequency change on unit level. Most commonly, available governor in each generator measures the system frequency in any time and compares it with the nominal frequency and finally corrective measures are deployed according to frequency difference within seconds [1]. The gain of the feedback loop in the primary frequency controller, which is called droop, is defined as follows [22]:

$$
R=-\frac{d f / f_{o}}{d p / P_{o}}
$$

Where $f_{o}$ is the nominal frequency and $P_{o}$ is the generator capacity. Indeed, droop is an important parameter in the frequency regulation that in thermal power plants is usually $4 \%$ to $5 \%$ and in hydro plants this value is around $2 \%$ to $3 \%$. If a generator has a $4 \%$ droop setting, it means that for every $1 \%$ change in frequency from reference, the power output of the turbine will change by $25 \%$. Figure 3 shows droop curve where vertical axis can be either speed or frequency.

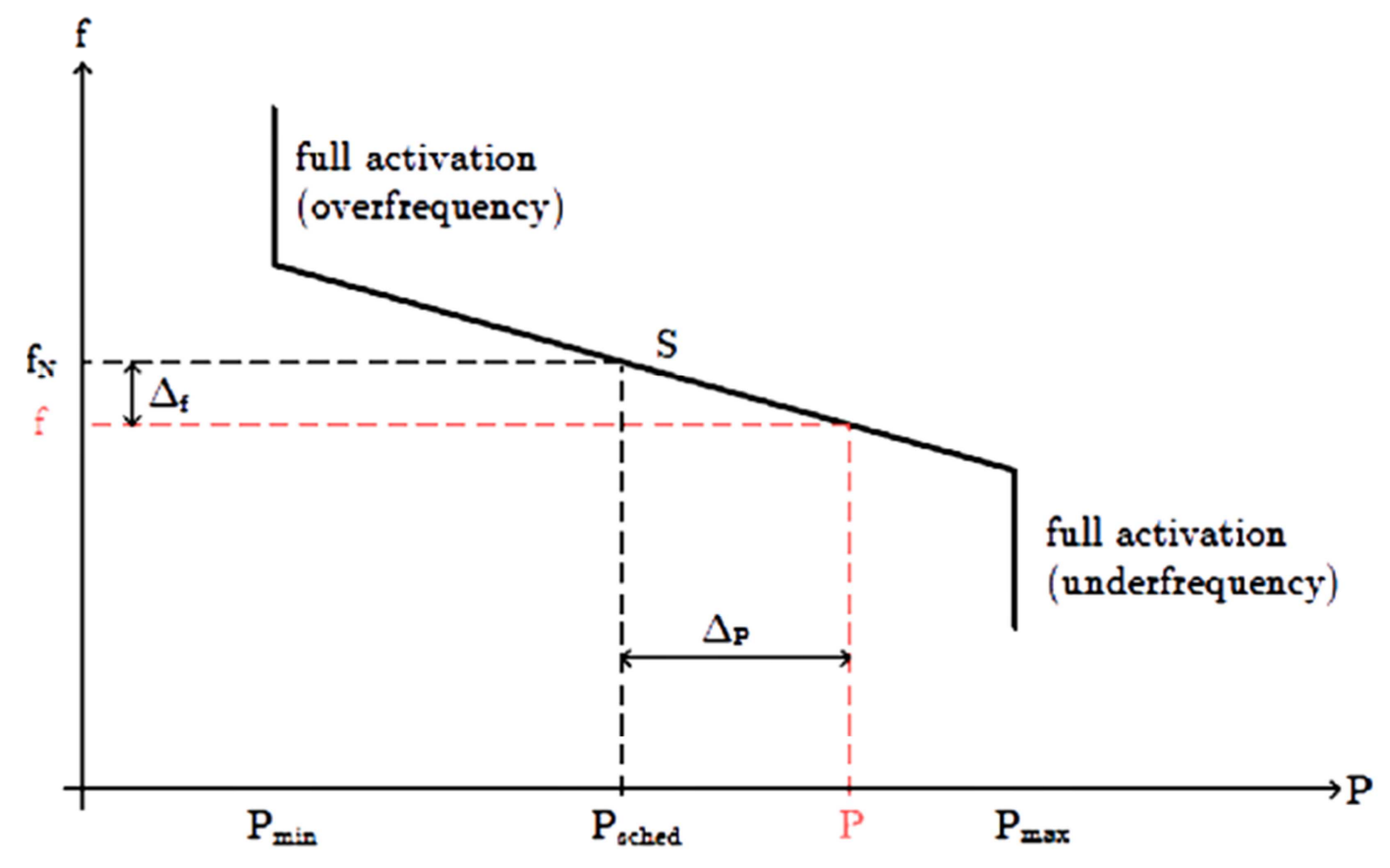

Figure 3. Droop curve.

It should be noted that primary frequency control is not intended to return the power system frequency to its nominal value, but only stabilize it on a unit-by-unit basis. Other control components (secondary and tertiary levels) are used to restore system frequency to its nominal level $(50 \mathrm{~Hz})$ [23]. In addition, to avoid unnecessary activation of primary frequency response, generators' governors usually have a dead band that is a region around their nominal frequency $\pm 20 \mathrm{mHz}$ where the primary frequency control is not activated. For instance, ENTSO uses a dead band $\pm 20 \mathrm{mHz}$; hence a units' primary frequency control is activated if the frequency deviation from nominal exceeds $\pm 20 \mathrm{mHz}$ [24]. Operation of a governor with respect to dead band is shown in Figure 4. 


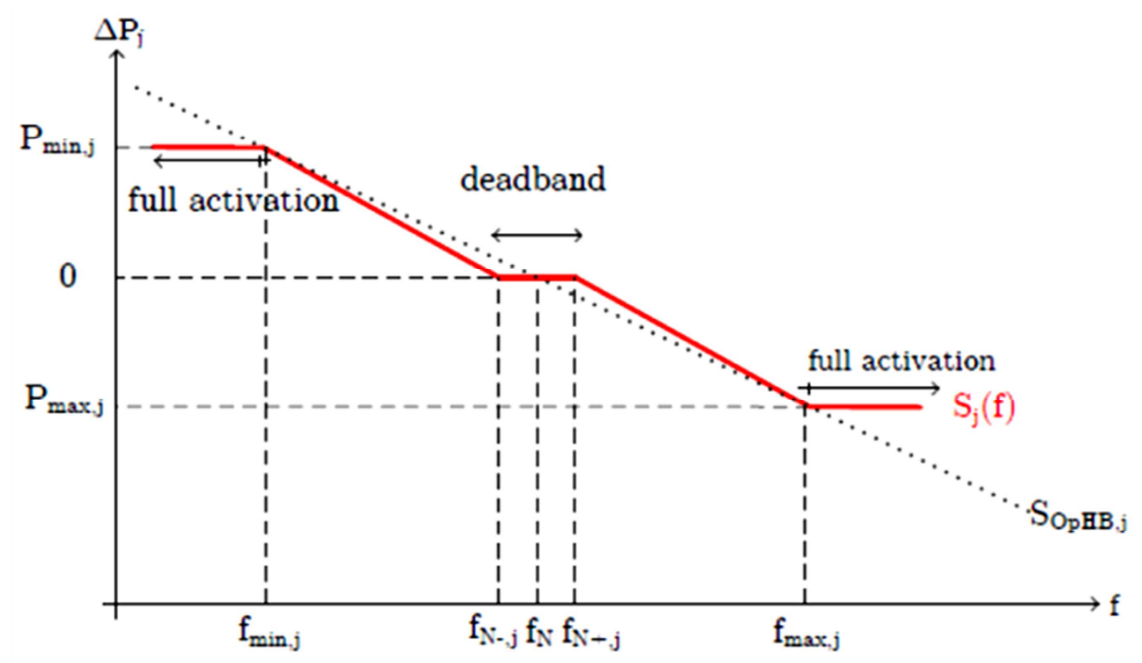

Figure 4. Droop curve with respect to dead band.

In Figure $4, \mathrm{f}_{\mathrm{N}-\mathrm{J}}$ and $\mathrm{f}_{\mathrm{N}+\mathrm{J}}$ show the dead band frequency range and $\mathrm{f}_{\mathrm{Min}, \mathrm{j}}$ and $\mathrm{f}_{\mathrm{Max}, \mathrm{j}}$ denote the minimum and maximum frequencies where full activation of primary control takes place. These frequencies are also known as break frequencies. When a contingency occurs in the power system, e.g., a large generator suddenly fails, system frequency falls rapidly due to imbalance between load and generation. The balance between load and generation should be restored immediately otherwise the power system will collapse. Therefore, after a contingency, when system frequency moves outside the generator governor dead band, autonomous generator governors provide immediate response, as shown in figure 5 , by incrementing their output in response to $-D \Delta f k$ subject to capacity and ramp limits of the unit in an attempt to bring back system frequency to target value. Secondary and tertiary frequency control is then utilized next to restore the system frequency to its nominal value (Figure 6) [19].

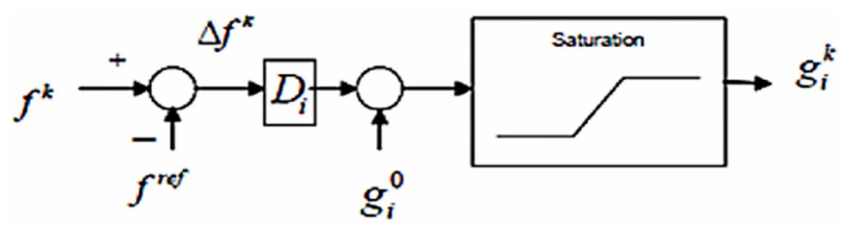

Figure 5. Primary frequency control of unit $i$ after $k$ contingency.

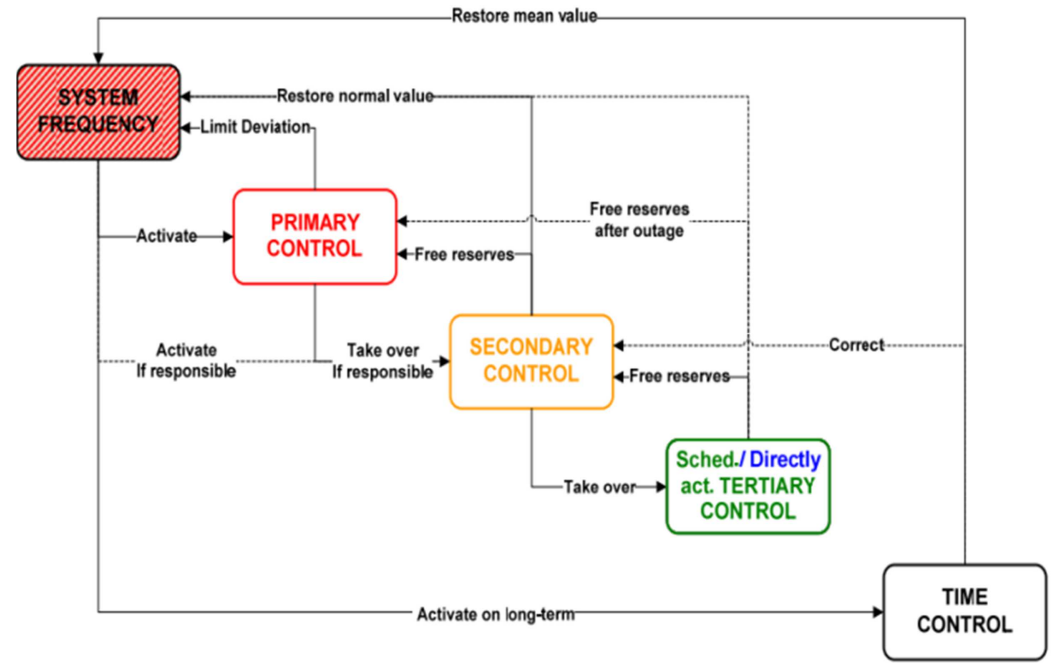

Figure 6. Different control actions in AC systems and their linkage.

In some of the generating units, the governor operation mode may be chosen by the operator in order to prevent a unit from contributing to frequency control. Indeed, in these generating units, the governor operation mode is switched off without the necessity to shut down the unit. This capability is implemented by defining adjustable parameters such as time delay and frequency dead band [25].

\subsection{Secondary Frequency Control}

Secondary control is normally a centralized system level reaction which brings back system frequency and exchanges with adjacent systems to pre-set values and restores the primary control for next probable contingency. This control which is known as Automatic Generation Control (AGC) is 
activated automatically or manually to reestablish unbalance between generation and load [22]. AGC operates in conjunction with Supervisory Control and Data Acquisition (SCADA) systems. SCADA collects information related to system frequency, generator outputs, and actual interchange between the system and adjacent systems and AGC, by using this information, computes an Area Control Error (ACE). ACE specifies whether a system is in balance or needs to make adjustments to its generation [22, 26-27]. Therefore, AGC automatically determines the output for generating units by sending set-points to generators that participate in the AGC in order to restore energy balance and frequency control [28]. Figure 7 shows control loops of both primary and secondary control components in a power system. It must be noted that the capacity identified and reserved for AGC is separate from the Operating Reserve.

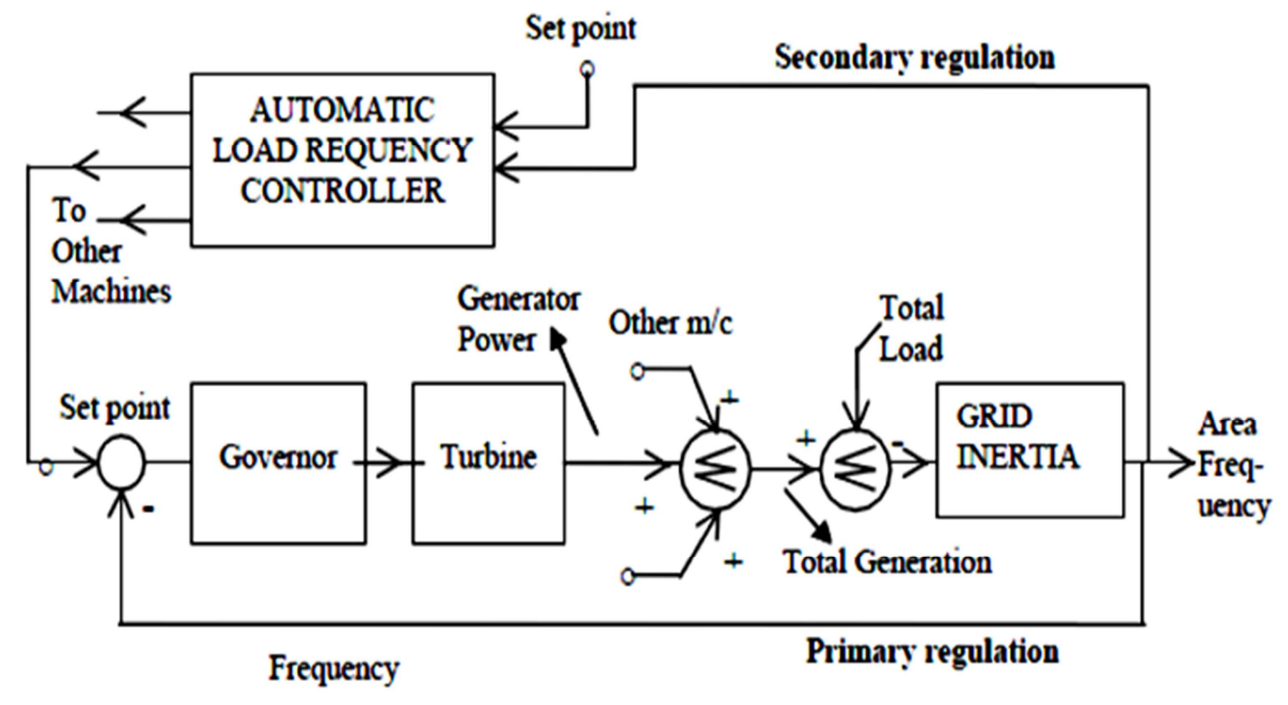

Figure 7. Control loops of both primary and secondary control.

\subsection{Tertiary Frequency Control}

If the secondary control is insufficient, tertiary control operates to return frequency to target value and restore the secondary control reserve. Tertiary frequency response is normally in the form of security constrained economic dispatch [6, 29]. During contingency, in order to restore an adequate secondary control reserve or to provide desired (in terms of economic considerations) allocation of this reserve within the set of generating units in service. Tertiary control may be achieved by means of: changing the set operating points of thermal power plant generation sets, around which the primary and secondary control acts; connection/ disconnection of pump storage hydro power stations operated the an intervention mode; altering the power interchange program; and load control (centralized tele-command system or controlled load shedding). The timing of the primary, secondary and tertiary control ranges and frequency response of a power system following a major generation trip is shown in Figure 8 [30]. Supplementary Reserve Capacity (SR) is frequency dependent reserve. Supplemental Reserve is that amount of operating capacity, some or all of which may not be connected to the interconnected network but which can be connected within 10 minute and fully applied to meet the requirements $[6,19,21]$.

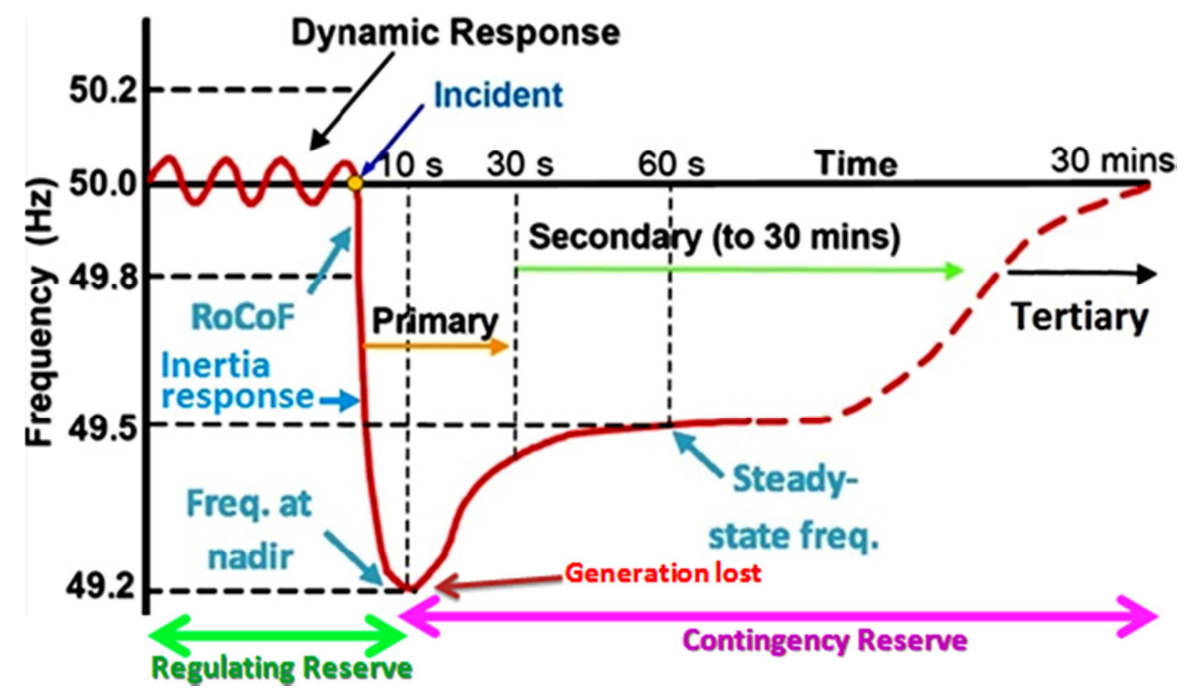

Figure 8. Example of frequency and reserve response following a major generating outage. 


\subsection{Characteristic of Each Frequency Control Level}

There are specific differences between each frequency control level. These differences and characteristics of these frequency control levels are compared and shown in Table 3 [6, 31-32].

Table 3. Comparison between Frequency Control Levels.

\begin{tabular}{llll}
\hline & Primary Control & Secondary Control & Tertiary Control \\
\hline Used Means & Governor & AGC Manual set- point & Spinning, non- spinning reserve \\
Control Method & Automatically & Automatically \& Manually & Manually \\
Control Place & Automatically & Centrally & Centrally \\
Control Signal & Local Sensor & Local Sensor or System operator & Local Sensor or System operator \\
Activation Time & Immediately & Depends on grid code & Depends on grid code \\
\hline
\end{tabular}

\subsection{Timing of Reserve in Power System}

In theory, a generating unit can take part in all three control levels. Figure 9 illustrates how its capacity would be divided. However, in practice, a generating unit might provide only one, two or none of these reserve services.

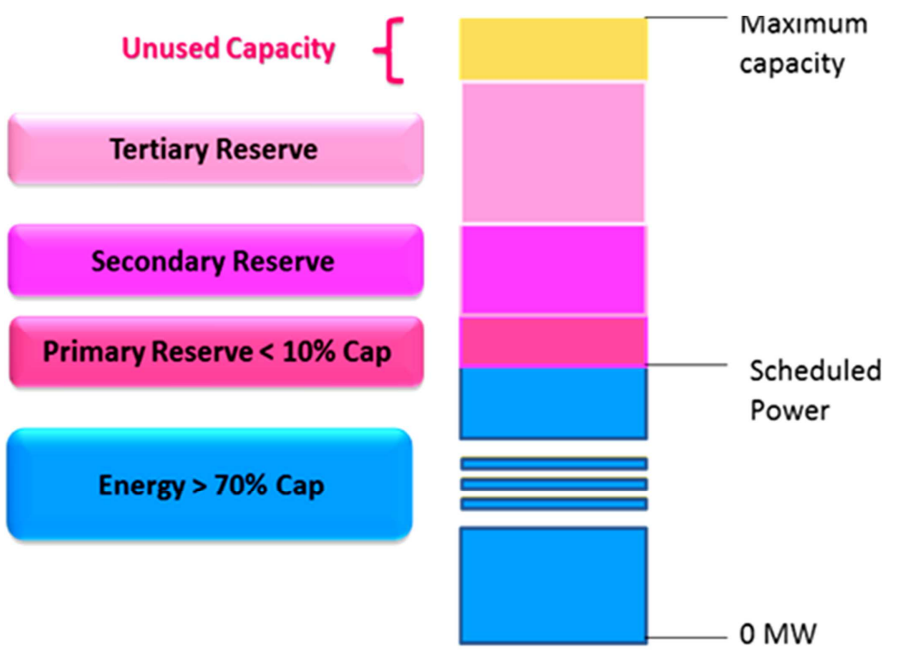

Figure 9. Allocation of the capacity that takes part in all three levels of frequency control.

It should be taken into account that exact timing requirement varies from region to region and each country has its specific reserve timing. Table 3 shows sample timing of several power systems. Different type of reserves is used at different frequency control level. A detailed survey has been conducted in European region, United States and Canadian regions [33-49]. The frequency regulation framework, reserve policy and technical specification of services are shown in the table-4 below.

Table 4. Timing of reserves in different systems.

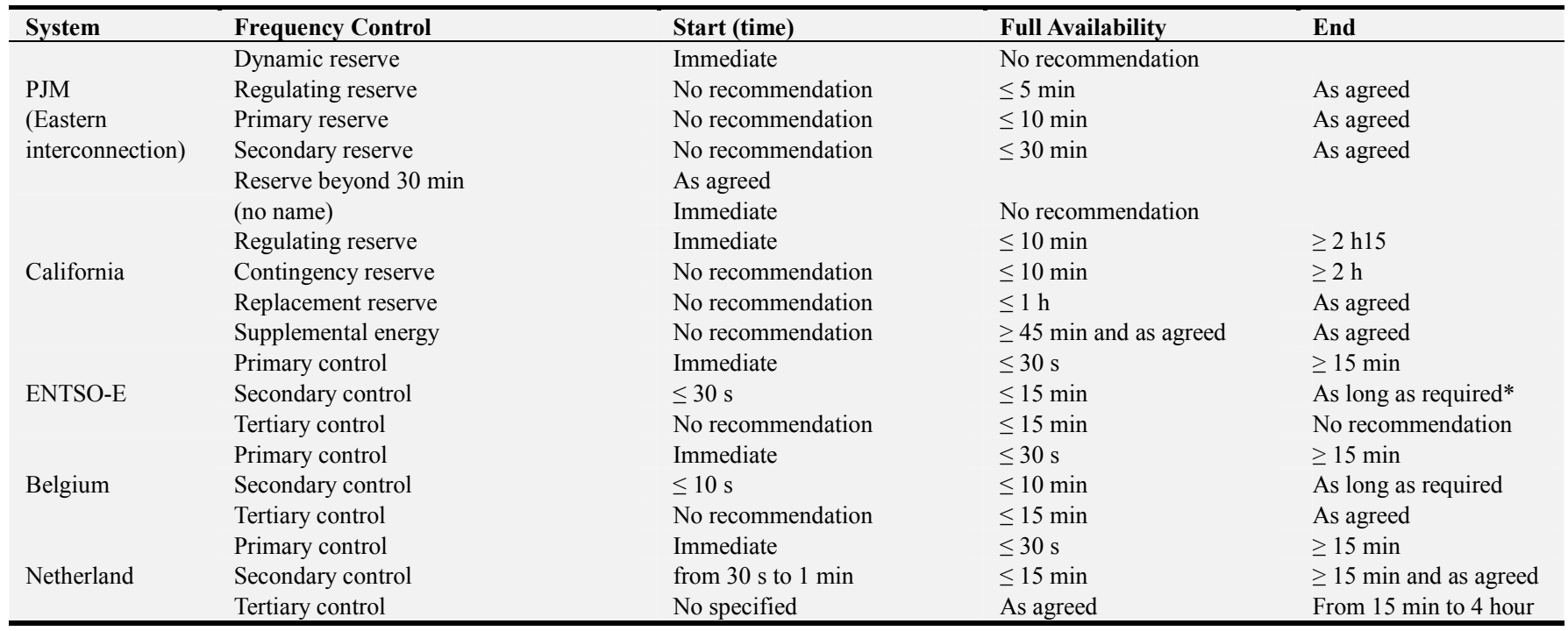




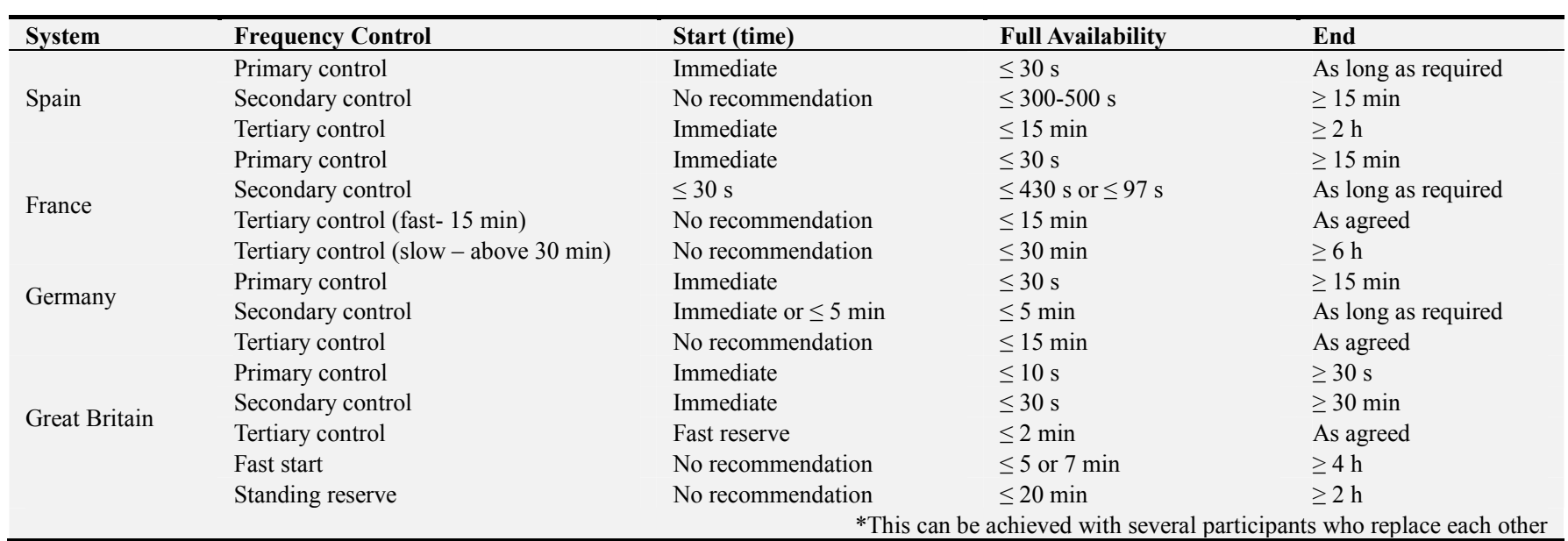

\subsection{Observation and Proposed Guideline}

From Table 3, it is shown that from definition and terminology of reserve varies among the regions. According to NERC terminology, categorization of reserve is little bit complex. NERC does not provide quantitative requirements for regulating reserve; reserve is only used for normal conditions.
On the other hand, ENTSO-E's secondary reserve is explicitly based on statistical trend and mostly comes from variability of loads. Secondary reserve is used for both contingencies and normal violations. NERC's categories of different reserve are shown in Figure 10 Based on table 3; a compression of frequency control mechanism is shown in figure 11 .

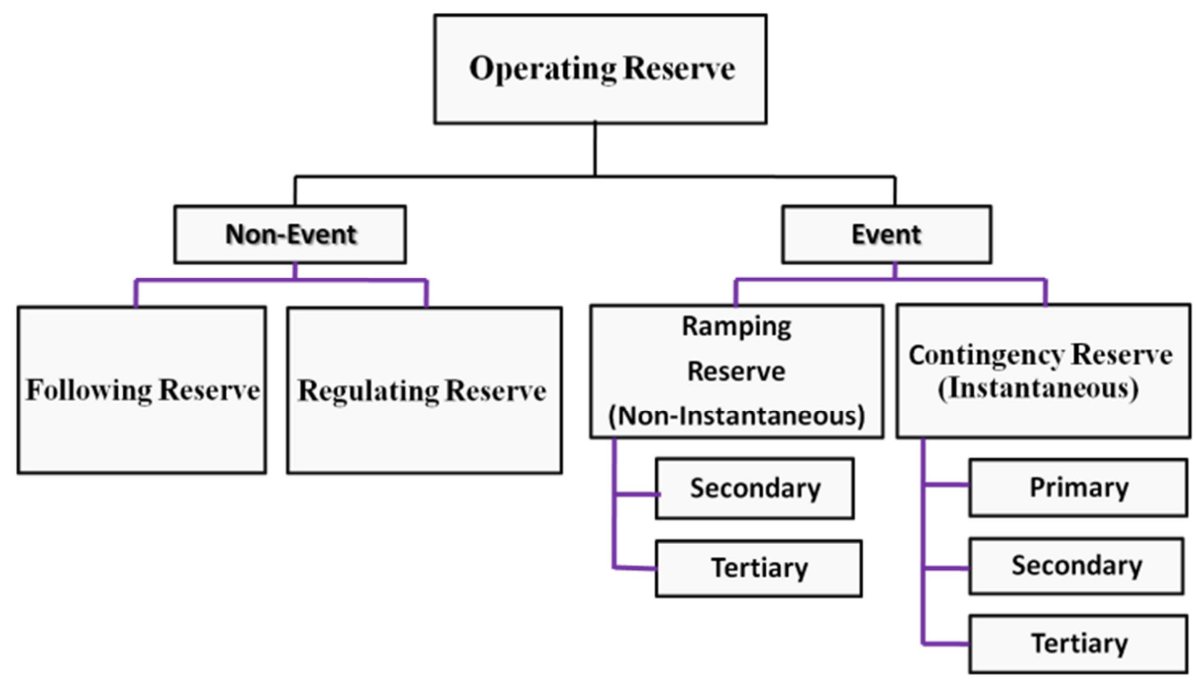

Figure 10. NERC Categories for Reserve.

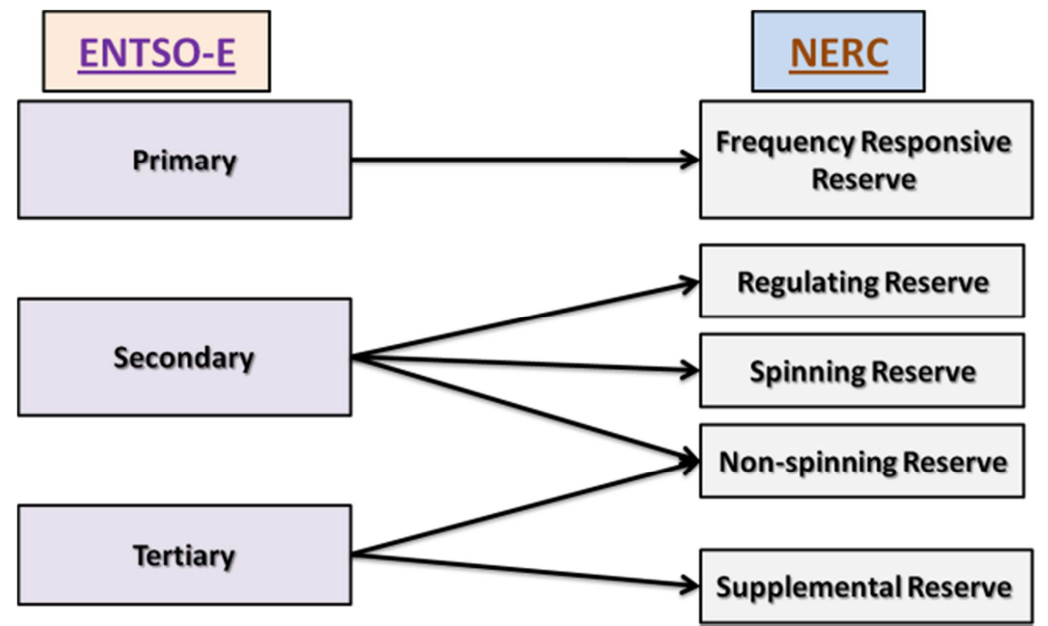

Figure 11. Comparison of frequency control mechanism of ENTSO-E and NERC. 
Proposed guideline and constraints: The guideline and constraints of acceptable levels for frequency are as follows:

a. In normal operation, the frequency should be maintained in $50 \pm 0.05 \mathrm{~Hz}$ range;

b. In event of N-1 contingency the frequency should not fall below $49.50 \mathrm{~Hz}$;

c. The frequency should not drop below lowest UFLS setting, even for very severe disturbances;

d. In case of the largest credible loss, the frequency should be restored to $49.80 \mathrm{~Hz}$ within one minute and to 49.90 $\mathrm{Hz}$ within 10 minutes;

e. After a disturbance, the operating reserve level in the system should be restored to normal level within 30 minutes; f. The transmission system voltage levels within the lower limit of $-5 \%$ and the upper limit $+5 \%$ of their rated voltages;

g. Under contingency conditions, transmission lines and transformers loading is $120 \%$ of the normal rating was taken into account.

Based on this guideline, the maximum regulating reserve capacity for each unit which should participates in frequency control program via its governor. Based on proposed guideline, the reserve level and frequency control mechanism is illustrated on figure 12. Here, the replacement and supplementary reserve come from in terms of non spinning reserve and tertiary frequency control. The detail of this reserve and control is described on our work [13].

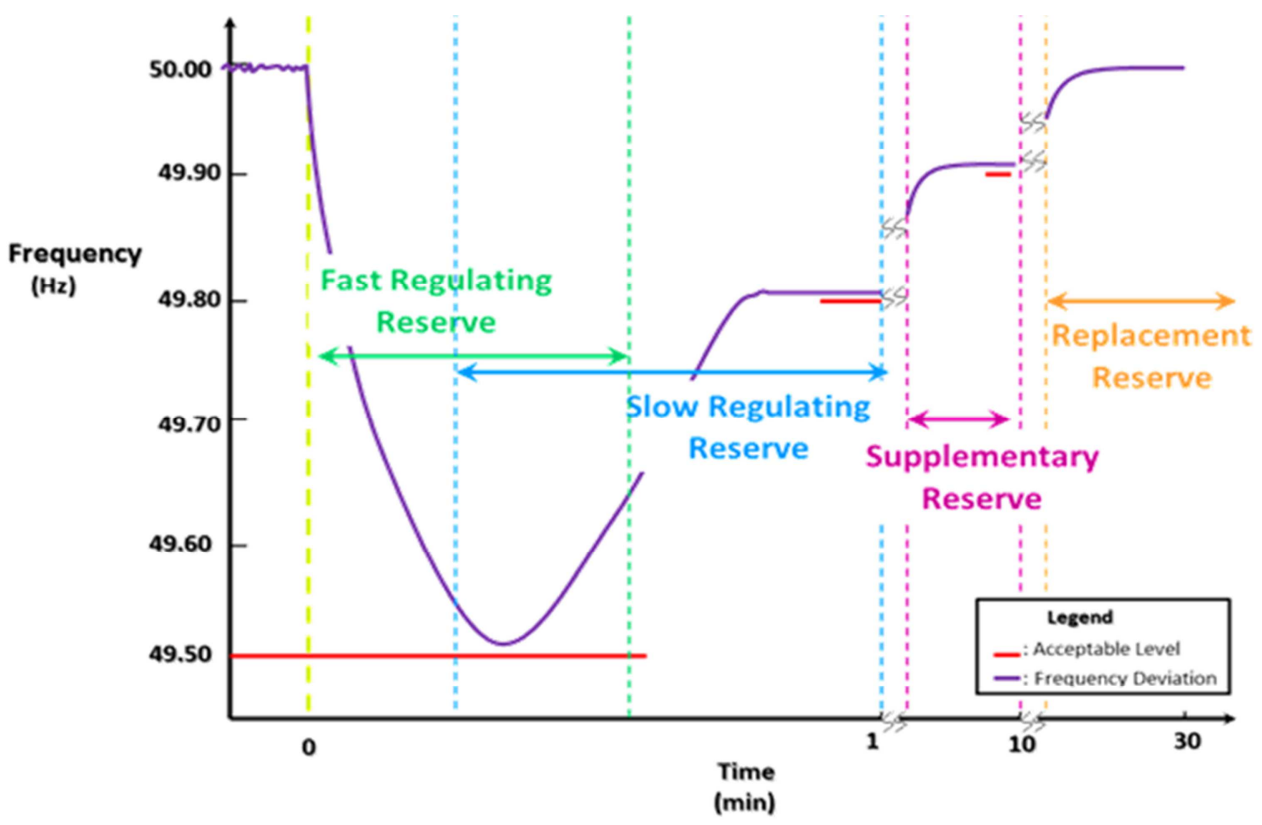

Figure 12. Contribution of OR at different frequency level.

\section{New Technologies Review for Enhancing Reliability}

In this section, all of the requirements for implementation of new technologies have been provided. Apart from the type of technology, there exist some steps which should be taken for implementation of the new technology which are pointed out in the following. In the following for each technology an overview has been provided. Moreover, the required steps and considerations have been introduced.

\subsection{WAMS}

A Wide Area Measurement System (WAMS) consists of advanced measurement technology, information tools, and operational infrastructure that facilitate the understanding and management of the increasingly complex behavior exhibited by large power systems. In its present form, a WAMS may be used as a stand-alone infrastructure that complements the grid's conventional supervisory control and data acquisition
(SCADA) system. As a complementary system, a WAMS is expressly designed to enhance the operator's real-time situational awareness that is necessary for safe and reliable grid operation [50]. Phasor measurement unit (PMU) is a device which is necessary for implementing WAMS in power system. A phasor measurement unit (PMU) is a device which measures the electrical waves on an electricity grid using a common time source for synchronization [51].

Time synchronization allows synchronized real-time measurements of multiple remote measurement points on the grid. The resulting measurement is known as a synchrophasor. PMUs are considered to be one of the most important measuring devices in the future of power systems. A PMU can be a dedicated device, or the PMU function can be incorporated into a protective relay or other device. A phasor network consists of phasor measurement units (PMUs) dispersed throughout the electricity system, Phasor Data Concentrators (PDC) to collect the information and a Supervisory Control And Data Acquisition (SCADA) system at the central control facility. Such a network is used in Wide 
Area Measurement Systems (WAMS). The complete network requires rapid data transfer within the frequency of sampling of the phasor data. The PDC correlates the data, and controls and monitors the PMUs [52]. At the central control facility, the SCADA system presents system wide data on all generators and substations in the system every 2 to 10 seconds. PMUs often use phone lines to connect to PDCs, which then send data to the SCADA or WAMS server. Additionally, PMUs can use ubiquitous mobile (cellular) networks for data transfer (GPRS,UMTS), which allows potential savings in infrastructure and deployment costs, at the expense of a larger data reporting latency[53]. However, the introduced data latency makes such systems more suitable for R\&D activities and near real-time monitoring, and limits their use in real-time protective systems. The primary merits of WAMS can be categorized as follow:

a). Operators can take immediate corrective actions, mainly because WAMS can provide early warning of deteriorating system conditions;

b). By taking immediate actions, WAMS avoids disastrous results of cascading effect of disturbances;

c). Improve power system reliability and visualization through the use of archived monitoring system data.

\subsection{Smart Grid}

Development of standards for communication and interoperability of appliances and equipment connected to the electric grid, including the infrastructure serving the grid; and identification and lowering of unreasonable or unnecessary barriers to adoption of smart grid technologies, practices, and services. In the following, the requirements of implementation of smart grid are introduced briefly:

a). Increased use of digital information and controls technology to improve reliability, security, and efficiency of the electric grid;

b). Exploiting full cyber-security for dynamic optimization of grid operations and resources;

c). Deployment and integration of distributed resources and generation, including renewable resources;

d). Development and incorporation of demand response, demand-side resources, and energy-efficiency resources;

e). Deployment of smart technologies (real-time, automated, interactive technologies that optimize the physical operation of appliances and consumer devices) for metering, communications concerning grid operations and status, and distribution automation;

f). Integration of smart appliances and consumer devices and provision to consumers of timely information and control options;

g). Deployment and integration of advanced electricity storage and peak-shaving technologies, including plug-in electric and hybrid electric vehicles, and thermal storage air conditioning;

h). Development of standards for communication and interoperability of appliances and equipment connected to the electric grid, including the infrastructure serving the grid; and

Regarding the mentioned requirements of smart grid, it can be concluded that it is strongly dependent on communication infrastructure and also needs a web of different parts which are constantly in communication with each other [54]. Implementation of smart grid in developing countries requires a great deal of time and effort to provide the infrastructures as perquisites for smart grid.

\subsection{Pump Storage Power Plant}

Pumped-storage hydroelectricity (PSH), or pumped hydroelectric energy storage (PHES), is a type of hydroelectric energy storage used by electric power systems for load balancing. The method stores energy in the form of gravitational potential energy of water, pumped from a lower elevation reservoir to a higher elevation. Off-peak electric power is used to run the pumps. During periods of high electrical demand, the stored water is released through turbines to produce electric power. Regarding type of operation, there exist two major type of hydroelectricity system. 1. Conventional 2. Pumped-storage. Each of these generation methods have their own pros and cons which should be considered with regard to the case of application.

\subsubsection{Conventional (Dams and Run-Off-the-Rivers)}

Some references discriminate between Run-off-the-river and conventional. However, in this report they are categorized in the same generation method because of lack of pumps. Most hydroelectric power comes from the potential energy of dammed water driving a water turbine and generator. The power extracted from the water depends on the volume and on the difference in height between the source and the water's outflow. This height difference is called the head. A large pipe (the "penstock") delivers water from the reservoir to the turbine. On the other hand, Run-off-the-river hydroelectric stations are those with small or no reservoir capacity, so that only the water coming from upstream is available for generation at that moment, and any oversupply must pass unused. A constant supply of water from a lake or existing reservoir upstream is a significant advantage in choosing sites for run-of-the-river.

\subsubsection{Pumped-Storage Plant}

This method produces electricity to supply high peak demands by moving water between reservoirs at different elevations. At times of low electrical demand, the excess generation capacity is used to pump water into the higher reservoir. When the demand becomes greater, water is released back into the lower reservoir through a turbine. Pumped storage is not an energy source, and appears as a negative number in listings. During periods of high electricity demand, power is generated by releasing the stored water through turbines in the same manner as a conventional hydropower station. During periods of low demand (usually nights or weekends when electricity is also lower cost), the upper reservoir is recharged by using lower-cost electricity from the grid to pump the water back to the upper reservoir. 
Hydropower can provide energy-balancing, storage capacity, and ancillary grid services such as network frequency control and reserves. This is due to the ability of hydroelectric plants to respond to potentially large electrical load changes within seconds [55].

\subsection{The Side-Effect of Renewable Energy on Reliability}

Nowadays, renewable energy resources have attracted many researcher' attention. However, there are challenges in integration of renewable energy resources into existing power system. Not surprisingly, each method of power generation has its pros and cons. Renewable energy of course is inexhaustible and environmentally friendly. Due to this important advantage, long term policies of international communities are towards boosting share of renewable energy resources in total electricity generation. Another advantage of renewable energy resources refers to small size renewable energy plants. Small individual power generators that are integrated into the grid reduce the impact of blackouts caused by a failure of centralized equipment or distribution lines. The distributed power technologies in general improve the overall system security [56]. However, as mentioned this merit is just for small size renewable energy plants. On the other hand, renewable energy resources, specifically in case of solar and wind resources are strongly dependent on weather condition. Hence, in the case of using a large capacity of solar and wind power a sudden change in weather condition drastically changes the generation. Accordingly, integrating large number of renewable energy resources into power system will endanger the system from reliability point of view. To overcome this problem, storage systems should be integrated into renewable energy plants [56,57]. This issue brings us to technical aspects of storage systems. Using storage systems for renewable energies requires a comprehensive study on its technical and financial issues. Moreover, there is no doubt on the fact that cost of renewable energy generation requires more capital investment and cost more in comparison to conventional fossil fuel plants. That's because of renewable energy integration requires new technologies such as converters, storage systems and turbines or solar modules. Although these technologies are progressing, they have not yet overcome fossil fuel plants from economic perspective. They are mainly used in remote areas for removing cost of installing expensive lines to these areas. In other words, only in special cases they are more interesting rather than conventional fossil fuel plants. From security and reliability point of view, increasing share of renewables in generation and supply of demand can adversely affect power system performance and stability [57]. This is mainly due to the fact that increasing the share of renewable energy resources in supplying electricity demand can reduce the inertia of system per installed capacity that as a result leads to decrease in the inherent response of system to frequency deviations. In other words, increasing the share of renewable energy in generation portfolio can increase the frequency control costs as well as load balance prediction costs to satisfy the reliability requirements of the system. So the necessity of fast regulating reserve is remarkably increased by enhancing the share of renewable resources in generation. In other word, for coping with the uncertainties on their inherent production nature, and also reducing the equivalent inertia of system per installed capacity, it is recommended that the share of hydro power plant would be increased in generation.

\section{Conclusions}

The preference of stability, reliability and optimal usage of energy resources aspects of unit commitment plans and dispatches is higher than economic aspects of that. It is so important to emphasize that not considering stability and reliability aspects in those plans can indirectly increase the operating cost. Using strict protection system for preventing instability can increase the probability of malfunctions. It is always recommended to adopt probabilistic approach to determine operating reserve in order to control frequency in an acceptable range. Another major issue in operation of power system refers to gathering sufficient data. In other words, the appropriate operation of system strongly depends on a complete data base. Another important issue should mention is to consider Hydro power resources as the main regulating frequency tool in frequency control program. The fact that during contingencies, system requires a very high reserve capacity that is not economically viable (for large hydro units) but very essential for system stability \& frequency control purpose.

\section{References}

[1] Jaleeli, Nasser, Louis S. Van Slyck, Donald N. Ewart, "Understanding automatic generation control," IEEE transactions on power systems 7, no. 3 (1992): 1106-1122.

[2] Berkel, Felix, Daniel Gorges, and Steven Liu, "Load-frequency control, economic dispatch and unit commitment in smart microgrids based on hierarchical model predictive control," Decision and Control (CDC), 2013 IEEE 52nd Annual Conference, IEEE, 2013.

[3] Jan Machowski, Janusz W. Bialek, James R. Bumby, "Power System Dynamics and Stability," John Wiley \& Sons, 1997.

[4] Allan, R. N, "Reliability evaluation of power systems," Springer Science \& Business Media, 2013

[5] NERC, CASIO., "Special Reliability Assessment: Maintaining Bulk Power SystembReliability While Integrating Variable Energy Resources - CAISO Approach," NERC, 2013.

[6] Milligan, Michael, et al, "Operating reserves and wind power integration: An international comparison," proc. 9th International Workshop on large-scale integration of wind power into power systems. 2010.

[7] J. F. Prada, "The Value of Reliability in Power Systems Pricing Operating Reserves”, Energy lab, MIT, Jun. 1985.

[8] Boroujeni, Hasan Fayazi, Meysam Eghtedari, Mostafa Abdollahi, "Calculation of generation system reliability index: Loss of Load Probability," Life Science Journal 9, no. 4 (2012): 4903-4908. 
[9] Dawes, Brett, and Kwan-Wu Chin, "A comparison of deterministic and probabilistic methods for indoor localization," Journal of Systems and Software 84.3 (2011): 442-451.

[10] Rao, Meesala Srinivasa, And Vallayil Na Naikan, "Review of Simulation Approaches in Reliability and Availability Modeling," International Journal of Performability Engineering 12, no. 4 (2016).

[11] Carvalho, Leonel de Magalhães," Using evolutionary swarms (EPSO) in power system reliability indices calculation, " $U$. PORTO, 2013.

[12] Al-Alawi, Ameer, Makarand Nagle, and Jinxiang Zhu,"Utilizing reliability indices to study generation adequacy," In Transmission and Distribution Conference and Exposition, 2010 IEEE PES, pp. 1-5. IEEE, 2010.

[13] Md Saleh Ebn Sharif, Mahmud-Ul-Tarik Chowdhury, Md Janatul Ferdous, Md Moniruzzaman, "An Efficient Method for Power System Frequency Control and Optimal Reserve Determination Considering Probabilistic Loss-of-Load Expectation Risk Index,” IEEE, EICT 2017, KUET.

[14] IK Odinakaeze, "Assessment of spinning reserve requirements in a deregulated system," USASK, Canada, 2010.

[15] Randell M. Johnson, "Integrated Resource Planning with PLEXOS, World Bank Thirsty Energy - A Technical Workshop," Morocco, 2014.

[16] Song, Z., Goel, L., \& Wang, P., "Risk based spinning reserve allocation in deregulated power systems," IEE Proceedings-Generation, Transmission and Distribution, 2 491-4, 2004.

[17] Song, Z., Goel, L., \& Wang, P. (2005), "Optimal spinning reserve allocation in deregulated power systems," IEE Proceedings-Generation, Transmission and Distribution, 152(4), 483-8.

[18] Hamon, Camille, "On frequency control schemes in power systems with large amounts of wind power," $P h D$ diss., KTH Royal Institute of Technology, 2012.

[19] ENTSO, "European Network of Transmission System Operators for Electricity (ENTSO-E)," Operation handbook, Appendix 1, Load-Frequency Control and Performance.' 2004.

[20] Sanghvi, Arun P., Neal J. Balu, and Mark G. Lauby, "Power system reliability planning practices in North America," IEEE transactions on power systems 6, no. 4 (1991): 1485-1492.

[21] North American Electric Reliability Corporation, "Reliability Standards for the Bulk Electric Systems of North America," NERC, November 2009.

[22] Bevrani, Hassan, "Robust power system frequency control," Vol. 85. New York: Springer, 2009.

[23] Egea-Alvarez, Agustí, Jef Beerten, Dirk Van Hertem, and Oriol Gomis-Bellmunt, "Hierarchical power control of multiterminal HVDC grids," Electric Power Systems Research 121 (2015): 207-215.

[24] ENTSO - Policy 1, "Load-Frequency Control, Final policy," 2014.

[25] Greacen, Chris, Richard Engel, and Thomas Quetchenbach, "A Guidebook on Grid Interconnection and Islanded Operation of Mini-Grid Power Systems Up to 200 kW," 2013.
[26] Pavlovsky, V., and A. Steliuk, "Modeling of Automatic Generation Control in Power Systems.' In PowerFactory Applications for Power System Analysis,”, pp. 157-173. Springer International Publishing, 2014.

[27] Bevrani, Hassan, and Takashi Hiyama, "Intelligent automatic generation control," CRC press, 2016.

[28] Yahia Baghzouz, "Power System Operation and Control," University of Nevada, Las Vegas, [Online]. Available at: http://www.egr. unlv. edu/ eebag/4.pdf

[29] Ela, Erik, Michael Milligan, and Brendan Kirby, "Operating reserves and variable generation," Contract 303 (2011): $275-3000$

[30] Teng, Fei, Marko Aunedi, Danny Pudjianto, and Goran Strbac., "Benefits of demand-side response in providing frequency response service in the future GB power system, " Frontiers in Energy Research 3 (2015): 36.

[31] Rebours, Yann G., Daniel S. Kirschen, Marc Trotignon, and Sbastien Rossignol, "A survey of frequency and voltage control ancillary services-Part I: Technical features," IEEE Transactions on power systems 22, no. 1 (2007): 350-357.

[32] Rebours, Yann \& Kirschen, D.s (2005), “A Survey of Definitions and Specifications of Reserve Services", UK, 2005.

[33] UCTE, "UCTE Operation Handbook", v 2.5E, the 20th of July 2004.

[34] UCTE, Online technical document, $\mathrm{http}: / /$ www.ucte.org/statistics/ terms_power_balance/e_default_explanation.asp".

[35] ELIA, "Rapport Opérationnel 2004", 2004.

[36] RTE, "Mémento de la sûreté du système électrique", 2004.

[37] VDN, "Transmission Code: Network and System Rules of the German Transmission System Operators", August 2003.

[38] VDN, "Leistungsbilanzen in Deutschland - Rahmen, Zielsetzung und Systematik", Janvier 2000.

[39] Tenne T, "http://www.tennet.org/english/system_services/ladder_size/m inimaal.asp".

[40] Ministerio de industria y energía, "Procedimientos de Operación", vol. BOE n 197, 20053, 1998.

[41] NERC, "Standard BAL-001-0 - Real Power Balancing Control Performance", 2005.

[42] NERC, "Standard BAL-002-0 - Disturbance Control Performance", 2005.

[43] PJM, "Manual 10: Pre-Scheduling Operations", Revision 16, 2003.

[44] PJM, "Manual 14D: Generator Operational Requirements", Revision 04, April 2005.

[45] CAISO, "Procedure M-402: Ancillary Service Procurement", the 1 st of October 2004.

[46] CAISO, "Spinning Reserve and Non-Spinning Reserve Settlements Guide (draft)", the 15th of March 2005.

[47] NGET, "Fast Reserve: Market Information for Tenders for October 2005", September 2005. 
[48] NGET, "Standing reserve market report 2005/2006", July 2005.

[49] J Zhu, G Jordan, and S Ihara, "The market for spinning reserve and its impacts on energy prices", proceedings of the IEEE Power Engineering Society Winter Meeting, 2000.

[50] M. D. Hadley, J. B. McBride, T. W. Edgar, L. R. ONeil and J. D. Johnson, Securing Wide Area Measurement Systems, Prepared by Pacific Northwest National Labo- ratory for DOE, Washington, 2007.

[51] E. Chen, H. S. Timorabadi and F. P. Dawson, "Real-time phasor measurement method including a GPS common time-stamp for distributed power system monitoring and control," Canadian Conference on Electrical and Computer Engineering, 2005., Saskatoon, Sask., 2005, pp. 441-444.

[52] Zhenyu Huang et al., "Performance evaluation of phasor measurement systems," 2008 IEEE Power and Energy Society General Meeting - Conversion and Delivery of Electrical Energy in the 21st Century, Pittsburgh, PA, 2008, pp. 1-7.

[53] Khairudin \& Hakim, L \& Mitani, Y \& Watanabe,"Phasor measurement technology based power system monitoring and control,"ARPN Journal of Engineering and Applied Sciences. 12. 3847-3852.

[54] Y. Yan, Y. Qian, H. Sharif and D. Tipper, "A Survey on Cyber Security for Smart Grid Communications," in IEEE Communications Surveys \& Tutorials, vol. 14, no. 4, pp. 998-1010, Fourth Quarter 2012.

[55] ENA-ETSAP, "Tech Brief Power_Grid Integration." IRENA, 2015.

[56] NIST, "ENERGY-Technologies to Enable a Smart Grid October," Gaithersburg, MD 20899, 2010.

[57] Islam, M. A. et al. "Global Renewable Energy-Based Electricity Generation and Smart Grid System for Energy Security.” The Scientific World Journal 2014 (2014): 197136. PMC. Web. 6 Oct. 2017.

[58] M. Shahidehpour, F. Tinney and Yong Fu, "Impact of Security on Power Systems Operation," in Proceedings of the IEEE, vol. 93, no. 11, pp. 2013-2025, Nov. 2005. 